\title{
Flow Resistance of Vessels with an Enlarged Total Cross-Sectional Area in the Midsection
}

\author{
Yanchun $\mathrm{Hu}^{*}$, Shenju Song and Yanxia $\mathrm{Hu}$ \\ Nanxin East Street, Xiandaiyiju 3-C-501, Jinan City, China
}

\begin{abstract}
To understand the hemodynamics of the microcirculation, we compared the resistance of vessels that either had an enlarged cross-sectional area in the midsection (denoted vessel 1) or had a uniform diameter (denoted vessel 2). The length of the two vessels and the pressure difference between the ends were equal. The two vessels were filled with water, and the volume of water flowing through the two vessels per second was measured. The volume of water flowing through vessel 1 was $4.05 \mathrm{ml} / \mathrm{sec}$, and the volume of water flowing through vessel 2 was $4.37 \mathrm{ml} / \mathrm{sec}$. Vessel 1 had a higher resistance, and water drained more slowly than from vessel 2 . These results demonstrate that vessels with a greater crosssectional area in the midsection have a lower flow than vessels with a constant cross-section, even though resistance in the midsection is lower when the cross-sectional area is greater.
\end{abstract}

Keywords: Resistance, capillary, hypertension.

\section{INTRODUCTION}

Blood vessels consist of a closed system of tubes that transport blood to all parts of the body [1]. Of the blood vessels, the arteries carry blood away from the heart, and the main arterial vessel repeatedly branches into smaller vessels. The diameters of blood vessels strongly decrease from the order of $25 \mathrm{~mm}$ in the aorta to only $5-30 \mu \mathrm{m}$ in the capillaries. According to Poiseuille's law, small changes in the vessel radius will result in large changes in the resistance. Capillaries are the smallest blood vessels, and red blood cells with diameters of $7 \mu \mathrm{m}$ must deform to pass through them [2]. In the past, a capillary bed consisting of many individual capillary vessels in parallel has been widely accepted to have a very low overall resistance to flow, even though the resistance of a single capillary is relatively high. Connecting arterioles and venules, capillaries form extensive branching networks; therefore, the total cross-sectional area of the capillary bed is clearly greater than that of the capillary entrance. Many previous studies have concluded that the increase in the total cross-sectional area of the capillary bed leads to a low overall resistance to flow. However, this theory has been disputed because a great reduction in the blood velocity occurs at the transition from arterioles to capillaries [3]. To obtain a better understanding of the physical phenomenon, we studied the in vitro flow of blood in tubes with a simple geometry. In this study, we proposed a simple tubing system to mimic the capillaries. This simple tubing system was in serial connection with a wide midsection. In this way, it was possible to evaluate whether an enlargement of the crosssectional area in the midsection could lead to a low overall resistance to flow.

\footnotetext{
*Address correspondence to this author at the Nanxin East Street, Xiandaiyiju 3-C-501, Jinan City, China; Tel: 13001731221;

Emails: lixing777521@163.com, yutaotai71@sohu.com and

zbf001282@sina.com
}

\section{MATERIALS AND METHODS}

\section{Materials}

For this project, the following were used: cylindrical vessels, flasks, connecting pipes, cylindrical containers, and a stopwatch.

A schematic diagram of the equipment is shown in (Fig. 1). In vessel 1 , there were three parts (A, B, and C). The length of each part was $15 \mathrm{~cm}$. Parts A, B, and C were in a series. Parts $\mathrm{A}$ and $\mathrm{C}$ were cylindrical vessels with equal dimensions (lumen diameter, $3 \mathrm{~mm}$ ). Part $\mathrm{B}$ was a cylindrical vessel (lumen diameter, $6 \mathrm{~cm}$ ) with one hole (lumen diameter, $3 \mathrm{~mm}$ ) at each end. Vessel 1 was wide in the midsection and narrow at each end (inlet and outlet). Vessel 2 was a cylindrical vessel with a constant dimension (lumen diameter, $3 \mathrm{~mm}$ ). The length of vessel 2 was $45 \mathrm{~cm}$, which was the same length as vessel 1 . The same two cylindrical containers were placed vertically. There was a hole (lumen diameter, 3 $\mathrm{mm}$ ) on the side of each cylindrical container. The vessels were separately connected with the cylindrical container. The experimental devices were filled with water. The height between the water level and the inlet of each vessel was 40 $\mathrm{cm}$ in both. According to Pascal's law, hydrostatic pressures at the inlets of each vessel were equal. Additionally, because the outlets of both vessels were exposed to the atmosphere, the pressure drop across both vessels was equal. When the water level dropped $10 \mathrm{~cm}, 250 \mathrm{ml}$ of water flowed through each vessel. Using a stopwatch to record the time for the water level to drop to $10 \mathrm{~cm}$, the volume of water flowing through the two vessels per second could be calculated.

\section{Results}

The test was repeated 10 times, and the possible differences in the flow rate between the two vessels were compared using an analysis of variance (ANOVA). The flow rates were significantly different at $p<0.05$. For vessel 1,250 
$\mathrm{ml}$ of water flowed through the vessel in 61.7 seconds, at a rate of $4.05 \mathrm{ml} / \mathrm{sec}$. For vessel 2, the same volume of water flowed through the vessel in 57.1 seconds, at a rate of 4.37 $\mathrm{ml} / \mathrm{sec}$. The water in vessel 1 drained more slowly than the water in vessel 2. According to the basic flow equation $\mathrm{Q}=\Delta \mathrm{P} / \mathrm{R}$, vessel 1 had a higher resistance than vessel 2 .

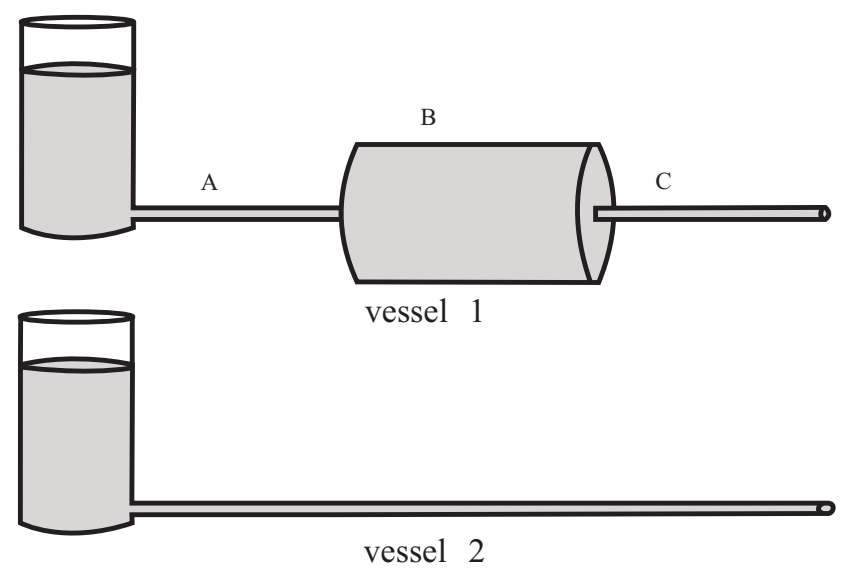

Fig. (1). Schematic diagram.

\section{DISCUSSION}

\section{Network of Vessels with Unequal Cross-Sectional Areas}

Of all of the factors that affect resistance, the radius of the vessel is the most important. Poiseuille's law states that resistance varies inversely with the fourth power of the vessel radius. For example, if the vessel radius is reduced to half, the resistance will increase 16-fold, illustrating how small changes in the vessel radius result in large changes in resistance. In this study, the pressure drop of both test vessels was equal. In vessel 1 , the lumen diameter of part B was much greater than parts $\mathrm{A}$ and $\mathrm{C}$, and according to Poiseuille's law, the resistance of part B should be much lower than parts A and C. According to the formula of overall resistance in a series $(\mathrm{Rs}=\mathrm{R} 1+\mathrm{R} 2+\ldots \ldots \mathrm{Rn})$, the overall resistance of vessel 1 should be approximately $66 \%$ that of vessel $2[4,5]$. In contrast, the water in vessel 1 drained more slowly than in vessel 2 .

Is a network of vessels with unequal cross-sectional areas a special case? Vessel 1 was a network of vessels with three parts that had unequal cross-sectional areas. The radius of part B was significantly greater than those of parts A and C. Separately, the resistance of part B should be much lower than those of parts A and C. However, when parts A, B, and $\mathrm{C}$ were connected, the conditions changed. Because the cross-sectional areas of the three parts and, the velocities of flow in the three parts differed. The law of conservation of matter states that mass or energy can neither be created nor destroyed [6]. For a network of vessels, the flow rate through any cross-section must be the same, and the velocity of flow of any part in the network of vessels is inversely proportional to the cross-sectional area. Because there was a large change in the cross-sectional areas between parts A and $\mathrm{B}$, the velocity of flow in part B should be much lower than those in parts $\mathrm{A}$ and $\mathrm{C}$, and there should be a large change in velocity between parts A and B. Although there was deceleration, there was also reacceleration between parts $\mathrm{B}$ and $\mathrm{C}$. The water flow in vessel 1 could not maintain a laminar state, meaning there was excessive friction in vessel 1 . If the resistance to the flow was caused by friction between the moving water and the wall of the vessel [7], the resistance to flow in vessel 1 should have been greater than that in vessel 2 . Poiseuille's law should be valid in a circulatory system only when the fluid flow is laminar and non-pulsating in horizontal cylindrical vessels of constant dimensions. In contrast to Poiseuille's conditions, the blood flow in the human circulation is pulsating and occasionally turbulent, and the blood vessels are not horizontally located, cylindrical, or inflexible. The blood viscosity is not constant or independent of the vessel diameter and flow.

\section{Parallel Network Resistance}

When several tubes with individual resistances of R1, $\mathrm{R} 2$...Rn are brought together to form a parallel network of vessels, the overall resistance for the parallel network (Rp) is reflected by the formula: $1 / \mathrm{Rp}=1 / \mathrm{R} 1+1 / \mathrm{R} 2+\ldots \ldots .1 / \mathrm{Rn}[4]$. This formula has been used to determine the resistance of capillary beds. According to this formula, the total resistance is less than that of any individual resistance, and if the number of vessels in parallel increases, the total resistance should decrease [8]. However, with the increase in the vessels in parallel, the total cross-sectional area should be greater than that of the inlet and outlet. The connecting vessels change into a network of vessels with a wide midsection and with narrow inlets and outlets. The characteristics of this network were similar to those of vessel 1, which contains an unequal cross-sectional area. In practice, when a uniform vessel opens several new branches in the midsection, if the crosssectional area of the inlet and outlet remains constant, the total resistance of this network should increase instead of decrease, as shown in (Fig. 2).



Fig. (2). The total resistance of vessel 1 is greater than vessel 2.

\section{Hydraulic Analogy to Ohm's Law}

The basic flow equation $(\mathrm{Q}=\Delta \mathrm{P} / \mathrm{R}$, blood flow $=$ pressure/resistance) summarizes the relationship between the pressure difference, blood flow, and vascular resistance. This equation is based on a fundamental law of physics, namely Ohm's law, which states that the current (I) equals the voltage difference $(\Delta \mathrm{V})$ divided by the resistance $(\mathrm{R})$. In electrical circuits, Ohm's law is used mathematically. The hydraulic analogy to Ohm's Law has been used to approximate blood flow through the circulatory system. However, the 
water analogy can create misconceptions, and awareness that electricity and water behave very differently is important [9].

\section{Resistance to Capillary Bed Blood Flow}

The blood pressure is known to drop most rapidly along small arteries and arterioles and to continue to decrease as the blood moves through the capillaries. Approximately $70 \%$ of the pressure drop occurs between the small arteries and capillaries, and the pressure drop in the arterioles is considered to be the product of resistance. However, there is a great change in the velocity of blood flow that occurs at the transition from the arterioles to the capillaries. The total collective cross-sectional areas of all of the capillaries in the systemic organs is more than 1,000 times that of the aortic root, and the total cross-sectional area of the capillaries is greater than that of the arterioles. As a result, when blood flows from the arterioles to the capillaries, the velocity will drop from approximately $5 \mathrm{~cm} / \mathrm{sec}$ to $1 \mathrm{~mm} / \mathrm{sec}$. Newton's First Law states that every body persists in its state of being at rest or in motion and continues in that state unless compelled by forces to change. When blood moves though the capillaries, its velocity decreases rapidly, and greater friction should exist between the blood and the capillary wall.

Therefore, when the radius of a tube is smaller, the resistance to fluid flow is larger. Compared with other smaller vessels in the body, capillaries have a much smaller diameter $(5-10 \mu \mathrm{m})$, which is barely sufficient for erythrocytes to pass through [10]. The friction between blood cells and the vascular wall will be greater.

In the body, most blood vessels are elastic tubular channels. Because the capillary beds are complex networks, they cannot be regarded as a rigid tube. When the heart beats the capillary beds will act as an elastic reservoir because of the distensibility of the tube and will store part of the left ventricular stroke volume. Thus, the blood pressure in the capillaries should be less relative to that of the arterioles, and the pressure drop between the arterioles and capillaries would appear relatively high. Acting as an elastic buffering chamber, the capillary beds store some of the blood in the cardiac systole, but the blood will flow more slowly through the capillary beds.

Capillary beds have multiple branches and parallel elements, with an unequal cross-sectional area. Friction between the moving blood and the walls of the capillary beds must be unevenly distributed, and thus it is doubtful that the arterioles are major contributors to the total peripheral vascular resistance.

\section{Hypertension}

If we support the idea that capillary beds are the major contributors to the total peripheral vascular resistance, the question of why the relaxation of vascular smooth muscles lowers the blood pressure must be answered. Capillaries lack vascular smooth muscle but are instead composed of a single layer of endothelial cells. There is no neural or local metabolic control of the capillary vessels, whereas the arterioles have much thicker walls with smooth muscles [11]. However, if most blood flowed directly from the arterioles to the venules and bypassed the capillary beds, the body's blood pressure would likely remain very low.

In fact, not all blood flows through the microvascular bed in systole. A large part of the blood flow through the microvascular bed occurs in diastole. For hypertensive patients, the blood perfusion in diastole is substantially different from that in normal patients. This difference in perfusion could be detected by photoplethysmography. Furthermore, the relaxation of vascular smooth muscles could influence blood perfusion in diastole of hypertensive patients. A study on blood perfusion changes in diastole of hypertensive patients may help understand why the relaxation of vascular smooth muscles should lower the blood pressure. In summary, because direct microvascular observations in vivo are not possible, in vitro analyses employing the principles of physics would be helpful in understanding the microvascular flow of blood.

\section{CONCLUSIONS}

For a network of vessels with a wide midsection and a narrow inlet and outlet, the overall resistance to flow should be great, even though the resistance of the midsection is lower than that of the other sections. Vascular resistance is a measure of how difficult it is to allow a fluid to flow through the entire tube. For a capillary bed, the presence of many branches does not indicate a low overall resistance.

\section{Highlight}

- An increase in the cross-sectional area in the midsection did not lead to a low overall resistance.

- For a capillary bed, the presence of many branches does not indicate a low overall resistance.

- A physics analysis in vitro will be helpful for understanding the microvascular behavior.

\section{CONFLICT OF INTEREST}

The author(s) confirm that this article content has no conflicts of interest.

\section{ACKNOWLEDGEMENT}

Declared none.

\section{REFERENCES}

[1] Pascual-Anaya, J.; Albuixech-Crespo, B.; Somorjai, I.M.; Carmona, R.; Oisi, Y.; Alvarez, S. The evolutionary origins of chordate hematopoiesis and vertebrate endothelia. Dev. Biol., 2013, 375(2), 182-192.

[2] Koutsiaris, A.G.; Tachmitzi, S.V.; Batis, N.; Kotoula, M.G.; Karabatsas, CH.; Tsironi, E. Volume flow and wall shear stress quantification in the human conjunctival capillaries and post-capillary venules in vivo. Biorheology, 2007, 44(5-6), 375-386.

[3] Lindbom, L.; Tuma, R.F.; Arfors, K.E. Influence of oxygen on perfused capillary density and capillary red cell velocity in rabbit skeletal muscle. Microvasc. Res., 1980, 19, 197-208.

[4] Mohrman, D.E.; Heller, L.J. Cardiovascular Physiology; McGrawHill Companies Inc: 2010: pp. 5-9.

[5] Pries, A.R.; Secomb, T.W.; Gessner. T.; Sperandio, M.B.; Gross, J.F.; Gaehtgens, P. Resistance to blood flow in microvessels in vivo. Circ. Res., 1994, 75, 904-915.

[6] Long, A.A.; Sedley, D.N. "Epicureanism: The principals of conservation". The Hellenistic Philosophers.: Translations of the principal 
sources with philosophical commentary. Cambridge University Press: Cambridge, 1987, pp. 25-26.

[7] Song, S.; Burleson, P.D.; Passo, S.; Messina, E.J.; Levine, N.; Thompson, C.I. Cardiac structure and function in humans: a new cardiovascular physiology laboratory. Adv. Physiol. Educ., 2009, 33(3), 221-229.

[8] Badeer, H.S. Hemodynamics for medical students. Adv. Physiol. Educ., 2001, 25(1-4), 44-52.

[9] Akers, A.; Gassman, M.; Smith, R. Hydraulic Power System Analysis. Taylor \& Francis: Newyork, 2006; pp. 299-329.
[10] Merkx, M.A.; Bescós, J.O.; Geerts, L.; Bosboom, E.M.; van de Vosse, F.N.; Breeuwer, M. Accuracy and precision of vessel area assessment: manual versus automatic lumen delineation based on full-width at half-maximum. J. Magn. Reson. Imaging, 2012, 36(5), 1186-93.

[11] Pries, A.R.; Secomb, T.W. Structural adaptation of microvascular networks and development of hypertension. Microcirculation, 2002, $9(4), 305-14$.

Received: September 20, 2013

Revised: October 01, 2013

Accepted: October 11, 2013

(C) Hu et al.; Licensee Bentham Open.

This is an open access article licensed under the terms of the Creative Commons Attribution Non-Commercial License (http://creativecommons.org/licenses/by-nc/3.0/) which permits unrestricted, non-commercial use, distribution and reproduction in any medium, provided the work is properly cited. 